\title{
The Effects of Cytotoxic Dose of Progesterone on Caspase 8 Activity Level in Colon Cancer (HT29) Cells
}

\author{
Sirati Moghaddam P*, Rabie Nezhad Ganji N, Azadnia A
}

\begin{abstract}
It has been shown that progestins can induce apoptosis in cancer cells. We exerted this laboratory experimental research to assess the effects of cytotoxic dose of progesterone on caspase 8 activity in colon cancer (HT29 cells) in cell culture. Cytotoxic concentrations $(0.01 \mathrm{mg} / \mathrm{ml})$ of progesterone was used in our study. HT29 cells were purchased from National Cell Bank of Iran (Pasteur Institute, Tehran, Iran). Cells were grown and incubated in standard situation. Then, cells were sub-cultured into $75 \mathrm{~cm} 2$ flasks, $96-w e l l$ plates or 6-well plates. Activity level of caspase 8 was evaluated using calorimetric assay $(405 \mathrm{~nm})$ through microplate reader. Analyses were conducted using the SPSS 20 and ANOVA. Our results indicated that exposure to $0.01 \mathrm{mg} / \mathrm{ml}$ of progesterone led to significant increase in caspase 8 activity compared to control cells.
\end{abstract}

Keyword--- Progesterone, Caspase 8, HT29 Cells.

\section{INTRODUCTION}

The HT-29 cell line is the most widely used colorectal adenocarcinoma cell line with epithelial morphology, which is used in many cellular studies. These cells were first obtained in 1964 from 44-year-old Caucasian female tumor cells with colon adenocarcinoma. HT-29 cells under the standard conditions have a non-spontaneous growth, and they form undifferentiated cell lines that provide a very suitable model for investigating the effects of various factors on these cells. These cells are susceptible to 5-flaurouracil and oxaliplatin chemotherapy drugs, which are standard treatment options for colon cancer. [1-2]

Progesterone is essential for maintenance of pregnancy. It inhibits the contractions of smooth muscle myometritis, blocks the activity of uterine collagenase, and modifies the activity of the proteolytic enzyme. Progesterone is the most primitive hormone among all reproductive hormones. Observational studies and randomized trials have suggested that estrogens and/or progesterone may lower the risk for colorectal cancer. Inherited variation in the sex-hormone genes may be one mechanism by which sex hormones affect colorectal cancer,

Parsa Sirati Moghaddam (MSc) *(corresponding author) is with the Department of Molecular and Cellular Sciences, Faculty of Advanced Sciences \& Technology, Pharmaceutical Sciences Branch, Islamic Azad University, Tehran, Iran.(IAUPS) (Parsa.st72@gmail.com)

Nima Rabie Nezhad Ganji (MSc) the Department of Molecular and Cellular Sciences, Faculty of Advanced Sciences \& Technology, Pharmaceutical Sciences Branch, Islamic Azad University, Tehran, Iran.(IAUPS)

Avid Azadnia (MSc) is with the Department of Plant Systematic and Ecology, School of Biology, Science Campus, University of Tehran, Tehran, Iran (avid.azadnia@ut.ac.ir) although data are limited. This is related to the presence of estrogen and progesterone receptors, with apparently higher concentrations in colon cancers than in adenomas. Epidemiological data and the finding of a significant reduction in colon cancer risk related to hormone replacement therapy (HRT), and in particular the length of HRT intake, indicate that progesterone/progestins have a preventive effect. [3.4]

Caspases are a family of endoproteases that provide critical links in cell regulatory networks controlling inflammation and cell death. The activation of these enzymes is tightly controlled by their production as inactive zymogens that gain catalytic activity following signaling events promoting their aggregation into dimers or macromolecular complexes. Activation of apoptotic caspases results in inactivation or activation of substrates, and the generation of a cascade of signaling events permitting the controlled demolition of cellular components. Activation of inflammatory caspases results in the production of active proinflammatory cytokines and the promotion of innate immune responses to various internal and external insults. Dysregulation of caspases underlies human diseases including cancer and inflammatory disorders, and major efforts to design better therapies for these diseases seek to understand how these enzymes work and how they can be controlled. $[5,6]$

Caspase- 8 is a member of the cysteine proteases, which are implicated in apoptosis and cytokine processing. Like all caspases, caspase- 8 is synthesized as an inactive single polypeptide chain zymogen procaspase and is activated by proteolytic cleavage, through either autoactivation after recruitment into a multimeric complex or trans-cleavage by other caspases. Thus, ligand binding-induced trimerization of death receptors results in recruitment of the receptor-specific adapter protein Fas-associated death domain (FADD), which then recruits caspase- 8 . Activated caspase- 8 is known to propagate the apoptotic signal either by directly cleaving and activating downstream caspases or by cleaving the $\mathrm{BH} 3$ Bcl2-interacting protein, which leads to the release of cytochrome $\mathrm{c}$ from mitochondria, triggering activation of caspase-9 in a complex with dATP and Apaf-1. Activated caspase-9 then activates further "downstream caspases," including caspase-8. Knockout data indicate that caspase-8 is required for killing induced by the death receptors Fas, tumor necrosis factor receptor 1 , and death receptor 3 . Moreover, caspase-8-/- mice die in utero as a result of defective development of heart muscle and display fewer hematopoietic progenitor cells, suggesting that the FADD/caspase-8 pathway 
is absolutely required for growth and development of specific cell types. [5,7]

\section{MATERIAL AND MethodS}

Cytotoxic concentrations $(0.01 \mathrm{mg} / \mathrm{ml})$ of progesterone was used in our study. HT29 cells were purchased from National Cell Bank of Iran (Pasteur Institute, Tehran, Iran). Cells were grown and incubated in standard situation. Then, cells were sub-cultured into $75 \mathrm{~cm} 2$ flasks, 96-well plates or 6-well plates. Activity level of caspase 8 was evaluated using calorimetric assay $(405 \mathrm{~nm})$ through microplate reader. Analyses were conducted using the SPSS 20 and ANOVA.

\section{RESULTS}

Our results indicated that exposure to $0.01 \mathrm{mg} / \mathrm{ml}$ of progesterone led to significant increase in caspase 8 activity compared to control cells.

\section{DISCUSSION}

In our study, we found that exposure of colon cancer cells to cytotoxic dose of progesterone led to increased activity of caspase 8 enzyme. Caspase- 8 is a cysteine protease that plays a pivotal role in the extrinsic apoptotic signaling pathway via death receptors. Therefore, progesterone induces apoptosis in colon cancer cells through extrinsic pathway.

In line with our findings, studies have shown that progestins have anticancer effects on various types of cancer cells, inducing apoptosis in cancer cell lines in vitro resulting in decreased proliferation rate in cells.

Research findings have shown that male and female sex hormones influence proliferation of cancer cells in different organs including prostate and other organs. Cellular and molecular studies have shown that sex steroid hormones act on genes expression by which can control apoptosis in target cells. [8] Human colon cancer cells are also affected by sex steroid hormones. In vitro and in vivo studies have revealed that sex steroid hormone including progestins have pivotal role in proliferation of colon cancer cells. [9] Antiproliferative effects of progesterone also has been demonstrated in a study in which colon cancer (HT29) cells proliferation is reduced when the cells are exposed to cytotoxic doses of progesterone. [10] The studies also have indicated that apoptosis in several types of cancer cells is associated with caspase 8 activity. [11] However, in contrast to our findings there are studies showing that progesterone has protective effect against apoptosis. [12]

\section{CONCLUSION}

In our study, we found that exposure of colon cancer cells to cytotoxic dose of progesterone led to increased activity of caspase 8 enzyme indicating that apoptosis occurred through extrinsic pathway in which caspase 8 is activated.

\section{ACKNOWLEDGMENT}

We appreciate all who helped us to exert this study.

\section{REFERENCES}

[1] Cohen E, Ophir I, Shaul YB Induced differentiation in HT29, a human colon adenocarcinoma cell line J Cell Sci 1999;112(16): 2657-66.

[2] Nautiyal J1, Kanwar SS, Yu Y, Majumdar AP. Combination of dasatinib and curcumin eliminates chemo-resistant colon cancer cells. J Mol Signal 2011 Jul: 20;6:7. doi: 10.1186/1750-2187-6-7

[3] Szekeres J, Bartho. Immunosuppression by Progesterone in Pregnancy.England,Japon:CRC Press; 1992

[4] Schindler AE. Long-term use of progestogens: colon adenoma and colon carcinoma. Gynecol Endocrinol 2007; 1:42-4.

[5] Mcllwain DR,Berger T,Mak TW. Caspase Functions in Cell Death and Disease.Cold Spring Harb Perspect Biol 2013; doi: 10.1101/cshperspect.a008656

[6] Kruidering M, Evan G. Caspase-8 in apoptosis: the beginning of "the end"? IUBMB Life 2000 Aug;50(2):85-90.

[7] Kuida K. Caspase-9. Int J Biochem Cell Bio 2000 Feb;32(2):121-4

[8] Honda S, Loher P, Shigematsu M, Palazzo JP, Suzuki R, Imoto I, Rigoutsos I, Kirino Y. Sex hormone-dependent tRNA halves enhance cell proliferation in breast and prostate cancers. Proc Natl Acad Sci 2015;112(29):E3816-25.

[9] Lointier P, Wildrick DM, Boman BM. The effects of steroid hormones on a human colon cancer cell line in vitro. Anticancer Res. 1992 Jul-Aug;12(4):1327-30.

[10] Tanaka Y, Kato K, Mibu R, Uchida S, Asanoma K, Hashimoto K,et al. Medroxyprogesterone acetate inhibits proliferation of colon cancer cell lines by modulating cell cycle-related protein expression. Menopause. 2008 May-Jun;15(3):442-53. doi: 10.1097/gme.0b013e31815 6fb77

[11] Atencio IA, Ramachandra M, Shabram P, Demers GW. Calpain inhibitor 1 activates p53-dependent apoptosis in tumor cell lines. Cell Growth Differ. 2000;11(5):247-253.

[12] Behera MA, Dai Q, Garde R, Saner C, Jungheim E, Price TM. Progesterone stimulates mitochondrial activity with subsequent inhibition of apoptosis in MCF-10A benign breast epithelial cells. Am J Physiol Endocrinol Metab. 2009 Nov; 297(5): E1089-E1096. 